\title{
ADOPTING IOT-BASED SOLUTIONS FOR SMART HOMES. THE PERSPECTIUE OF THE ROMANIAN USERS
}

\author{
Irina Albăstroiu ${ }^{1 *}$, Calcedonia Enache ${ }^{2}$, Andrei $\mathrm{Cepoi}^{3}$, Adrian Istrate ${ }^{4}$ \\ and Teodora Liliana Andrei ${ }^{5}$ \\ ${ }^{122334) 51}$ Bucharest University of Economic Studies, Romania
}

Please cite this article as:

Albastroiu, I., Enache, C., Cepoi, A., Istrate, A. and Andrei, T.L., 2021. Adopting IoT-Based Solutions for Smart Homes. The Perspective of the Romanian Users. Amfiteatru Economic, 23(57), pp.325-341.

\section{Article History}

Received: 30 December 2020

Revised: 29 January 2021

Accepted: 6 March 2021

\section{DOI: $10.24818 / \mathrm{EA} / 2021 / 57 / 325$}

\begin{abstract}
IoT (Internet of Things) is a concept that defines a world in which all objects are connected to each other via the Internet. The ability of smart devices to connect, communicate and transfer data has enabled the innovation and development of various solutions for industry, business organizations and final consumers. In this article, we have chosen to discuss the solutions related to smart homes.

Thus, our paper presents, in the first part, the conceptual delimitations regarding IoT, areas of application, and characteristics of the solutions dedicated to smart homes, showing that adoption of IoT-based smart home solutions has been too little addressed in the literature. Most of the work in the field insists on the technical aspects and only subsidiarily deals with the issues regarding the level of understanding of the IoT smart home concept by potential or actual users and the degree of adoption and use of these solutions. In order to cover these gaps identified in the literature, we presented, in the second part of the paper, the methodology and results of an exploratory research, conducted on a sample of 471 persons, which allowed us to identify the socio-demographic characteristics of the respondents (users of IoT solutions), level of understanding the IoT concept, degree of the adoption and, also, the associated benefits and challenges, from the perspective of the Romanian users. We also developed a binary logistic regression model, for in-depth analysis of the results and for correlating the findings of our research with those of other studies.
\end{abstract}

Keywords: Internet of Things, smart home, smart device, automation, monitoring and remote control.

JEL Classification: L86, O33

* Corresponding author, Irina Albăstroiu - e-mail: irina.albastroiu @ com.ase.ro

\section{Authors' ORCID:}

Irina Albăstroiu: https://orcid.org/0000-0003-4159-0572

Calcedonia Enache: https://orcid.org/0000-0001-7069-6662

Andrei Cepoi: https://orcid.org/0000-0002-0413-5389

Adrian Istrate: https://orcid.org/0000-0001-9724-456X

Teodora Liliana Andrei: https://orcid.org/0000-0003-3487-6310 


\section{Introduction}

Kevin Ashton, technology pioneer, cofounder and executive director of the Auto-ID Center at MIT (Massachusetts Institute of Technology), used for the first time syntagma Internet of Things - IoT in a presentation he made in 1999 in order to describe the network connecting objects in the physical world to the Internet. Referring later to this concept, Ashton (2009) affirmed that IoT has the potential to change the world, as has happened before with the Internet.

Although the concept appeared two decades ago, technologies that condition and support IoT are constantly evolving; being related with an amalgam of existing and developing technologies applied in a new context, even finding an appropriate definition of the term is not an easy task. Many authors have tried to expose the important attributes, to define and capture the essence of IoT (Gigli and Koo, 2011; Lee and Lee, 2015; Madakam et al., 2015; Whitmore, Agarwal and Li, 2015; Ben-Daya et al., 2017), approaching Internet of Things especially from the perspective of a global network infrastructure that connects physical and virtual objects by exploiting data capture and communication capabilities, based on object identification, sensors and connections in order to development independent cooperation services and applications. Over time, the term has evolved, describing, into a more generic meaning, a network of entities connected by any form of sensor, allowing these entities to be located, identified and even controlled and remotely operated (Onete, Pleșea and Albăstroiu, 2017)

An IoT solution involves hardware components (processors, sensors, gateways, controllers, and switches), software (standalone and integrated platforms), and services (device lifecycle management, remote monitoring, and deployment services). Adopting these solutions is a way to boost productivity, keep us healthier (or at least more careful and concerned with this aspect), make transportation more efficient, reduce energy consumption or make our homes more comfortable. This last-mentioned aspect, namely the implications of IoT technologies on our homes, is subject of the present article.

Although home automation has been in question since the '80s (Horrigan, 1987), the concept of smart home has been drawing attention recently due to IoT. A smart home is an advanced form of traditional home automation, but IoT technologies are taking a step further by introducing centralized control. A home with IoT solutions is the one wherein electrical, electronic, and household appliances are connected to a central monitoring and control system, so that can be automatically turned on and off at certain times or if certain events occur. The devices are connected via the Internet, and the customer can remotely adjust access in the house, temperature, lighting, etc., but also functions of the smart TV, refrigerator, oven etc.

The adoption of IoT smart home solutions has been too little addressed in the literature. Most papers in the field are based on the technical aspects, presenting the architecture, structure and functionalities of such systems and associated security issues (Strengers, 2013; Lia et al., 2018; Sowah et al., 2020) and only subsidiarily deal with issues regarding the level of understanding the IoT smart home concept by potential or actual users and the degree of adoption and use of these solutions Although there are regional analyzes and market reports (Fortune Business Insights, 2020; Mordor Intelligence, 2020; Research Reports World, 2020), still, in the scientific literature are presented mainly empirical analyzes on specific groups (young people in the digital generation, elderly with disabilities, various categories of 
patients etc. (Le, Nguyen and Barnett, 2012; Lee and Park, 2020)), but the popularization of such services requires more general discussions for various classes of users. Also, we did not identify any scientific articles dealing with the situation from Romania or the perspective of the Romanian users of smart home IoT solutions.

In this context, our paper aims to present and analyze the adoption of IoT smart home solutions in Romania and the benefits and challenges from the perspective of the Romanian users. To achieve this goal, the article is structured as follows: this introductory part (describing the general scientific framework) is followed by a review of the literature, which focuses on conceptual delimitations regarding IoT, areas of application and features of smart home solutions. Forwards is the methodology section, presenting the purpose, objectives, applied method and research tools. Results of this research, performed to identify the level of adoption of smart home solutions in Romania, are analyzed related to other similar studies in third section of the paper. The article ends with conclusions part, where is also mentioned the limits of the research and possible directions for future analyzes.

\section{Literature review}

\subsection{Internet of Things - conceptual insights}

In recent years, Internet of Things (IoT) has attracted significant attention from different researchers. Nevertheless, there is no universal definition of IoT, as stated by Whitmore, Agarwal and Li (2015). However, analyzing definitions in the literature, Lynn et al. (2020) notice there are two main conceptualizations: technical perspective (IoT is considered an ecosystem of technical artifacts (Weyrich and Ebert (2016)) and socio-technical perspective (IoT recognizes actors and associated processes, being recognized especially the role of connected objects (Shin, 2014)).

However, IoT paradigm has evolved, from the approach concerning what can be connected to the network, to the approach based on what can be done with objects connected to the network (Ibarra-Esquer et al., 2017).

Regarding the thing or object that can be connected to the network, from the IoT perspective, it can be any machine, device, application, computer, virtual or physical object involved in a communication that could connect to the Internet and capable to create, request, consume, redirect, or access digital information (Elkhodr, Shahrestani and Cheung, 2013). There are related concepts mentioned in the literature, such as smart pieces/articles/products, "smart" being a term used to describe things or processes that have the ability to calculate, connect and communicate to differentiate themselves from machines and equipment working in isolation.

Concerning what can be done with these (inter)connected things or objects, it can be said that act as providers and/or consumers of data related to physical world. Recent definitions (Whitmore, Agarwal and Li, 2015; Ibarra Esquer et al., 2017) focus on some capabilities of these objects/things, such as:

- networking - set of communication functionalities that allow them to connect and make their identification, sensor measurements, and other attributes available to external entities such as other smart objects or systems; 
- identification - have an unique identifier and can be recognized either by an electronic tag or a label that can be read by another object or device;

- localization and tracing - built-in sensors to obtain data on their precise physical location and actual condition;

- actuation - can be remotely controlled to trigger actions that have an effect on physical reality;

- $\quad$ processing - can process information obtained by themselves or received via the Internet and possess basic computing capabilities which can be used to make decisions about themselves and their interactions with external entities.

Taking into account existing studies in the literature, we note the following aspects: most of the previous studies have presented IoT application from the perspective of business organizations (Schlick, Ferber and Hupp, 2013; Osterrieder, Budde and Friedli, 2020) or communities/cities (Wirtz, Weyerer and Schichtel, 2019; Janik, Ryszko and Szafraniec, 2020), a multitude of papers focus on technical issues, presenting IoT architecture, design and implementation (Gubbi et al., 2013; Bing, 2014; Weyrich and Ebert, 2016) and only a few studies have investigated the impact of IoT on the final consumer (Gao and Bai, 2014; Shin and Park, 2017). This is one more reason to consider particularly important the consumer perspective concerning IoT, as we will proceed in this article.

An important aspect approached in the literature refers to data protection and security. Sicari et al. (2015) and Dian, Vahidnia and Rahmati (2020) indicate as important security challenges those regarding access control, authentication confidentiality, privacy, compliance, middleware security, data security etc.

\subsection{IoT application areas}

The development of IoT technologies is currently far-reaching, despite the pandemic, which has slowed the pace of development of many such high-potential sectors. The purpose of using this technology varies, its value is increasing, as well as the budgets allocated for its development and application (Nižetić et al., 2019). Given the forecasts for their spread over the next 10 years, it is estimated that over 125 billion IoT devices will connect to the global network (Anstee, 2019). Also, the expected investments in IoT technologies are remarkably high, and is estimated will reach over 120 billion USD in 2021 , with an annual growth rate of $7.3 \%$, (Columbus, 2018).

IoT application areas have expanded and changed over the years. A research by Atzori, Iera and Morabito (2010) indicated as major areas: transport, logistics and health. Five years later, a study by I. Lee and K. Lee (2015) identified key areas for the IoT footprint, including production, finance and insurance, retail, and intelligence services. Recently, Nizetic et al. (2019) show among the areas of IoT applicability the following: transport, agriculture, health, energy, smart home, smart wearables, and smart city.

The capability of smart devices to connect, communicate and transfer data using advanced sensors, data networks and computing systems has enabled innovation and development of IoT devices and applications for the industrial sector (Industrial IoT), business organization (Commercial or Enterprise/Business IoT) and individual user or final consumer (Consumer IoT). 
- Regarding Industrial IoT, applicability of IoT technologies would allow an increased efficiency regarding the production process by giving a smooth communication over the network of operators and machines. Industrial processes have expanded through $M 2 M$ (Machine-to-Machine) communication, sometimes referred to as the Internet of Industrial Objects, but also include links to human interfaces. An efficient and enhanced industrial process is defined by the way sensors are connected, how they process data collected and the output of these sensors. (Chen et al., 2020). A key point in the industry will be the design development, production, and integration of various sensors in industrial applications (Li et al., 2020).

- Regarding the business sector (Commercial/Business or Enterprise IoT), IoT projects addressed to companies are varied - from optimizations of production flows (which are also related to the industrial sector - Industrial IoT, presented above) to the implementation of intelligent solutions for the office area (associated, up to a point, with those related to the concept of smart home, corresponding to the category Consumer IoT).

Transportation and logistics are sectors where IoT applications are in high demand (Porru et al., 2020). Already in the transportation industry we have the concept of Internet of vehicles (Shen, Fantacci and Chen, 2020), which have both impact and potential to develop. Some of the IoT application in the case of vehicles are related to creating a fully autonomous vehicle, location, direction, planned journey of the autonomous vehicle, monitoring of safety systems, prevention and avoidance of crash and accidents, improving the safety and service life of vehicles (Saki, Abolhasan and Lipman, 2020).

Efficient demand side management with accurate and flexible smart metering technologies are key factors to enable smart power management in smart grids. The most important role of IoT technologies in smart grids is to save electricity (Rishav et al., 2019), driving to a rational and fair distribution of energy.

Waste management, as an incumbent part of a circular economy, is another problematic area, including for business organizations. Various solutions are being developed to enhance the smart waste management (Das et al., 2019). There are solutions dedicated towards the smart monitoring of waste bins (Dhana Shree et al., 2019), to detect the level of bin filling, waste temperature, if any fire threat, trash bin vibration and garbage discharge, location of the trash bin and sanitation service operator etc.

- With respect to Consumer IoT, relatively recent studies (Porter and Heppelmann, 2014; Ostrom et al., 2015) suggest that every connected product has potential to offer value-added business, creating a new market after the product is already sold to its final customer.

Portable and health monitoring devices fall into this category, being devices that can be worn (wearables) by the user - smart watches, bracelets, trackers even clothes, shoes etc. The sensors together with the increased computation capacity of the smart watches, can help to make complex actions, such as payment management (Hsu and Lin, 2016). Also, smart wearables technology focus on sensor that can also collect health data such as heart rate, blood pressure, oxygen level in blood, skin temperature, vitamin levels, glycemic index, ketosis, effort and stress levels, and other general information which can help improve wellness observation levels (Zhang et al., 2020). IoT may be used to diagnose and administrate a proper treatment to patients (Muthu et al., 2020), assistance to elderly people by monitoring general health condition and nutrition status (Nivetha et al., 2020), rehabilitation monitoring at home after a disease (Bisio et al., 2019). 
Smart home devices refer to various interconnected devices that can communicate to improve the habitat of the user's home. Most of the tasks associated with a house management can be self performed or remotely managed thus saving time and effort for the individual. Some of these smart devices and technologies are lighting solutions, entertainment devices, home appliances, surveillance cameras, door lock systems, home sensors, voice recognition or activation home products, remote controls and many more (Le, Nguyen and Barnett, 2012; Lia et al., 2018; Yang, W. Lee and H. Lee, 2018). These are associated with the concept of smart home, which will be the subject of the next section and the central point of the research related to present paper.

\subsection{IoT-based solutions for smart home}

Although home automation has been in question since the '80s (Horrigan, 1987), as home security systems, lighting systems with motion sensors, automation of garage doors and gates, etc., the concept of smart home has been drawing attention recently due to IoT.

Nowadays, most modern homes already have some degree of "intelligence" because many appliances already have built-in sensors or electronic controllers; however, these fall into the category of automation systems, but are not exactly what we mean today by smart home. IoT smart home takes things a step further by introducing centralized control. Devices communicate between themselves, as well as with the user, to create an environment that matches the user's lifestyle. Therefore, the IoT smart home is a concept that adds to the traditional features of automation and remote control two essential attributes, namely interconnection and contextual adaptation. (Yang, W. Lee and H. Lee, 2018). Also, the smart home system requires a smartphone application or a web portal as a user interface to interact with an automated system.

Smart housing technologies and applications were initially used to manage environmental systems, such as lighting and heating (Ricquebourg et al., 2006). Currently, due to technological development, smart home application monitors users' activities and the internal environment, but also offers services that meet specific requirements and needs. Recently, smart home applications are evolving as they integrate artificial intelligence (AI) (Yang, W. Lee, and H. Lee, 2018). For instance, products such as Amazon Echo and Google Home have become a central hub for smart home gadgets and their voice-activated assistants, providing comfort in homes. Examples can also be the intelligent remote-control module developed by Chinese manufacturer Xiaomi (which can be inserted into all home appliances, such as refrigerators, air purifiers, air conditioners, washing machines, etc.) and Apple HomeKit (which provides voice support as a hub to communicate, configure and control smart devices in the Apple kit). In brief, this evolution is presented in table no. 1.

Table no. 1. Evolution of smart home

\begin{tabular}{|l|c|c|c|}
\hline Year & Phase & Technical background & Main function \\
\hline $1990 \mathrm{~s}$ & Home automation & Broadband Internet & Household automation \\
\hline $2000 \mathrm{~s}$ & Home network & Smart phone and app & Remote monitoring and control \\
\hline $2010 \mathrm{~s}$ & Smart home & $\begin{array}{c}\text { Internet of Things (IoT) and } \\
\text { Artificial Intelligence (AI) }\end{array}$ & Context awareness and adaptation \\
\hline
\end{tabular}

Source: Yang, W. Lee and H. Lee, 2018, p.2

Despite its long history and growing interest, applications and technologies in this category have not been widely accepted, mainly due to lack of infrastructure, expensive devices and, implicitly, limited consumer demand. However, IoT solutions for housing have become 
more popular in recent years as they have become more accessible and simpler through the development of information technology. Thus, the global smart home solutions market is expected to reach $\$ 246.42$ billion by 2025 , at an annual growth rate (CAGR) of $25 \%$ over the 2020-2025 forecast period (Mordor Intelligence, 2020b).

IoT-enabled house equipment and devices allow for a home to be more "intelligent", remote controllable, and interconnected (Yang, W. Lee, and H. Lee, 2018). There are various associated benefits mentioned in literature (Perera et al., 2017; Johannesen, Kolhe and Goodwin, 2019), such as improving comfort and lower costs resulting from better resources management, especially energy. IoT devices are constantly being developed to allow low consumption of household appliances and to forecast electricity consumption in homes.

Regarding the challenges associated with these devices, Risteska Stojkoska and Trivodaliev (2017) comment on the problematic aspect of data transmission, both in terms of volume and speed, given that action should normally be done instantly. Associated with data transfer is the aspect of network protocols and the need for interoperability between smart devices that do not belong to the same brand. Also, a problem of all IoT devices is maintaining confidentiality, securing data, and ensuring privacy.

\section{Research methodology}

As we indicated throughout the entire article, aspects regarding the architecture of smart home IoT solutions (Strengers, 2013; Lia et al., 2018; Sowah et al., 2020) and those regarding the advantages (Perera et al., 2017; Johannesen, Kolhe and Goodwin, 2019), challenges and security issues (Risteska Stojkoska and Trivodaliev, 2017) have been frequently addressed in the literature. The same statement is not valid when it comes to level of understanding the concept and degree of adoption of these solutions, as most studies have either applied the Technology Acceptance Model (TAM) or the Unified Technology Acceptance and Use Theory (UTAUT) or targeted only specific groups, especially the elderly and/or those with various health problems and young people. In order to cover these gaps identified in the scientific literature, we intended to present in this article the results of a more extensive research that we conducted to identify the degree of smart home IoT solutions usage by Romanians from various socio-demographic categories. We mention that our research focused on several aspects regarding the adoption of IoT solutions in Romania, but in this article we will focus only on those solutions for smart homes.

Thus, the aim of the research was to determine the degree of smart home IoT solutions usage in Romania. Subsequent to this goal, the main objectives of our research were to:

- O1: know the socio-demographic characteristics of the respondents - namely, Romanian users of IoT solutions for smart homes;

- O2: establish the level of understanding of the Internet of Things (IoT) concept;

- O3: identify the main IoT solutions used for smart home;

- O4: highlight the benefits and challenges related to these solutions, from the perspective of Romanian users;

- O5: determine the extent to which certain socio-demographic variables influence the adoption of IoT smart home solutions. 
This research was based on a standard methodology, which is applied in opinion survey. The method of data collection was the use of a self-administered questionnaire. The questionnaire was posted on the website www.isondaje.ro and was distributed as a link by e-mail to personal contacts of the authors and through social networks LinkedIn and Facebook. The beginning section of the questionnaire provides a brief explanation of its purpose to provide a common frame of reference for all potential respondents.

The sample used in the research was 471 persons. Given the limited sample size, this online questionnaire-based study is an exploratory research.

Data collection took place between April and June 2020.

IBM SPSS Statistics Version 26 software was used for descriptive statistics, but also for the binary logistic regression model.

\section{Results and discussions}

The socio-demographic characteristics of the respondents are presented in table no. 2 . We mention that in the questionnaire were answer options regarding age over 65 years and the level of primary or secondary education, but none of the respondents were included here. Thus, our sample consisted of people aged between 18 and 65 years, most are men $(56.4 \%$, although the difference is relatively small because $43.6 \%$ of respondents are women), young people ( $40.1 \%$ of those surveyed are included in the category 18-25 years), with bachelor's and even master's or Ph.D degree, most of the respondents (43.6\%) having incomes between 2000-4000 lei and living in urban area (89.5\%).

Table no. 2. Characteristics of the respondents

\begin{tabular}{|c|c|c|}
\hline \multicolumn{2}{|r|}{ Characteristics } & $\%$ \\
\hline \multirow[t]{2}{*}{ Gender } & Male & $56.4 \%$ \\
\hline & Female & $43.6 \%$ \\
\hline \multirow[t]{5}{*}{ Age } & $18-25$ years & $40.1 \%$ \\
\hline & $26-35$ years & $26.2 \%$ \\
\hline & $36-45$ years & $20.3 \%$ \\
\hline & $46-56$ years & $9.3 \%$ \\
\hline & 55-65 years & $4.1 \%$ \\
\hline \multirow[t]{6}{*}{ Income (RON) } & Under 1000 & $8.7 \%$ \\
\hline & $1001-2000$ & $13.4 \%$ \\
\hline & $2001-3000$ & $21.5 \%$ \\
\hline & $3001-4000$ & $22.1 \%$ \\
\hline & $4001-5000$ & $14 \%$ \\
\hline & Over 5000 & $20.3 \%$ \\
\hline \multirow[t]{2}{*}{ Education level } & High school and secondary education & $16.3 \%$ \\
\hline & Undergraduate and postgraduate studies & $83.7 \%$ \\
\hline \multirow[t]{2}{*}{ Residence } & Urban area & $89.5 \%$ \\
\hline & Rural area & $10.5 \%$ \\
\hline
\end{tabular}

Source: Research data processed by authors with statistical program SPSS

Most of the respondents (82\%) stated they use IoT devices and applications for their home, which allow remote control and automation. Corroborating with the characteristics of the sample, we can accomplish our first research objective $(O 1)$, outlining the socio- 
demographic characteristics of Romanian users of IoT smart home solutions who answered our questionnaire, these being mainly young people, male, with average income (between 3000 and 4000 lei, given the average net salary in Romania in that period, namely 3200 lei, according to INS (2020)), educated, with completed university or postgraduate studies and living in urban areas. From the perspective of age and education level, these results correlate with those of the ANCOM (2019) study on Romanian users of IoT solutions, although that study does not strictly refer to smart home solutions, but generally to IoT technologies. That research also shows that most household incomes of the respondents are higher than 6000 lei, but in the case of our research the users' incomes were targeted. Also, other research in the field (Zanocco et al., 2020) found that inclination towards the idea of smart home appears mainly among young people, and the largest rate of interest was registered in the case of males.

It is important to note that only those who answered affirmative to the filter question (related to the knowledge and understanding of the IoT concept) accepted the invitation to complete the questionnaire. To accomplish the second objective of our research $(O 2)$, an analysis of the answers was necessary and showed that most of those who accessed the questionnaire knew the meaning of the term (471 from 534 persons). Subsequently, they were asked to choose from a list one or more terms or collocations associated with IoT, and the main chosen were smart device (25.5\% of responses), portable and/or wearable device $(14.6 \%)$, interconnected objects $(13 \%)$, remote monitoring $(12.3 \%)$ and remote control $(12.1 \%)$. We mention that the fewest answers were for automation $(7.1 \%)$, which indicates that respondents can also differentiate between home automation and smart home.

It is found that respondents monitor, control and remotely operate via IoT solutions mainly smart TVs, ventilation and air conditioning systems, access and security systems (including flood and smoke sensors, motion sensors, surveillance cameras etc.), as well as heating systems (figure no. 1). Thus, indicating the solutions categories, we achieved the third objective of our research $(O 3)$. It is also important to mention that most research indicates smart TVs among the main devices for which IoT solutions are applied. Also, other audiovideo systems and entertainment devices are mentioned in other studies, which does not result from our study, highlighting that utility prevails for Romanian consumers.

The fourth objective of our research $(O 4)$ was accomplished through questions of the questionnaire related to main advantages, but also problems associated with the use of IoT solutions for smart home. Thus, the main benefits were related to saving time and energy (44.2\% of responses), making live easier (39.8\%) and improving the home comfort (23.4\%), and problems, understood also as barriers, were linked to dependence on technology (32\%), high cost of devices (30\%), fear and distrust related to confidentiality and security (28.5\%). These results correlate with those of the ANCOM (2019) study on Romanian users of IoT solutions (although that study does not strictly refer to smart home solutions, but to IoT technologies, in general), because participants in that study mentioned benefits such as comfort, security and optimization, and the biggest fears are those regarding personal data (theft/loss, confidentiality, complexity of the information collected), respectively, cost of the smart devices.

For a deeper interpretation of the results and to accomplish the ultimate research objective (O5), we will use the binary logistic regression model, similar to the one presented by Peng, Lee and Ingersoll (2002). The binary model, in which the dependent variable is a dichotomous one (has two values, usually symbolized by 0 and 1), is used to show whether 
an event occurred or whether a statistical unit has a particular property or not. We further purpose to quantify econometrically the relationship between the determinants and the option of the respondents to use smart home IoT solutions.

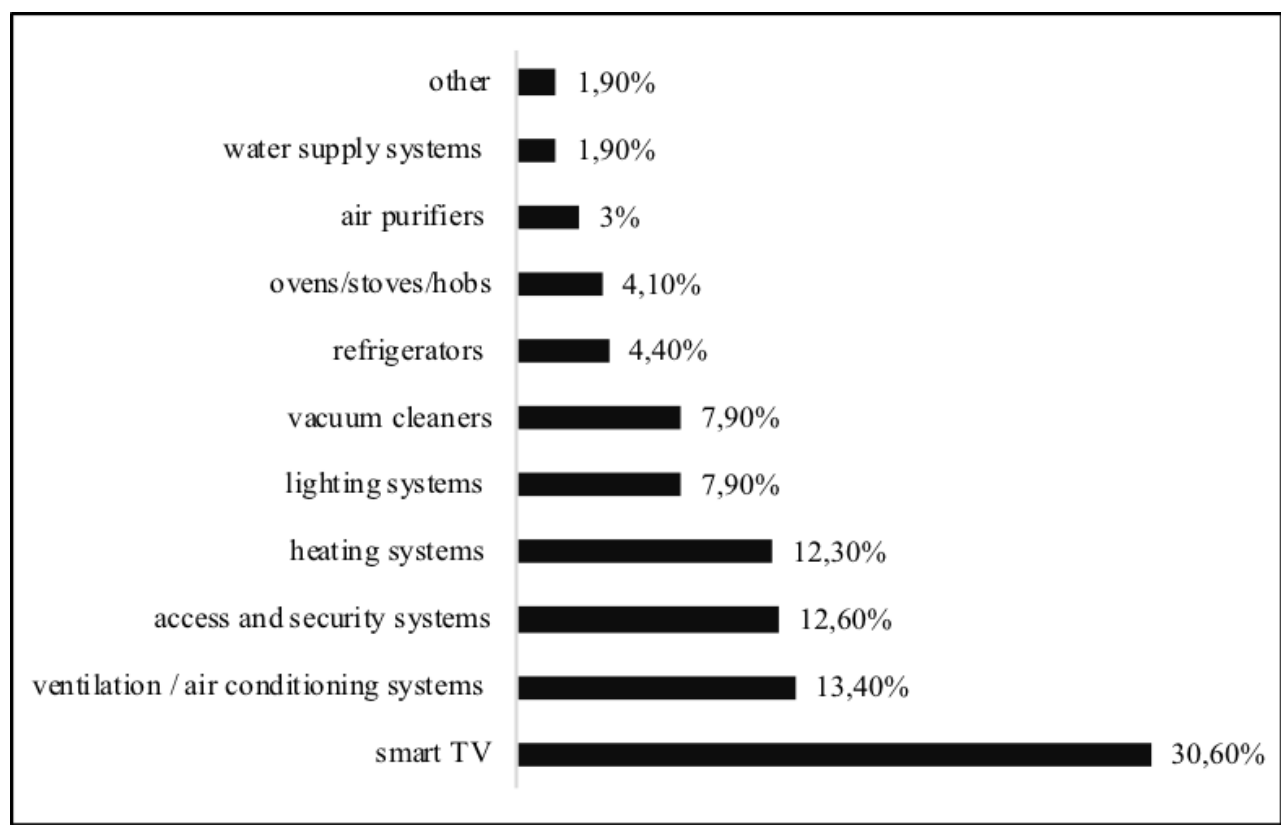

Figure no. 1. Respondents' weight hierarchy regarding the use of devices, appliances and systems monitored, controlled and operated by IoT solutions

Source: Research data processed by authors with statistical program SPSS

The variables included in the analysis are:

- PSH - use of IoT solutions for smart home (independent, dichotomous, categorical/nominal variable, with values 0 - if the person does not use such IoT solutions and $1-$ if the person uses such IoT solutions);

- SP - gender (dependent, dichotomous, categorical/nominal variable, with values 0 - for female person - and 1 - for male person);

- VP - age (dependent, dichotomous, categorical/nominal variable, with values 1 - if the person is aged between 18-35 years - and 2 - if the person is aged between 36-65 years);

- VEP - income (dependent, multinomial, categorical/nominal variable, related to the 6 income groups, having values 1 - if the person has an average monthly income below 1000 lei, 2 - average monthly income between 1001-2000 lei, 3 - average monthly income between 2001-3000 lei, 4 - average monthly income between 3001-4000 lei, 5 - average monthly income between 4001-5000 lei, 6 - average monthly income over 5000 lei).

To estimate the model parameters, the records at the level of the sample of 471 people were used. The results obtained are shown in table no. 3. 
Table no. 3. Results of binary logistic regression model

\begin{tabular}{|c|c|c|c|c|c|c|}
\hline & B & S.E. & Wald & df & Sig. & $\operatorname{Exp(B)}$ \\
\hline SP & .010 & .255 & .002 & 1 & .969 & 1.010 \\
\hline VP & .971 & .331 & 8.602 & 1 & .003 & 2.640 \\
\hline VEP & .406 & .100 & 16.577 & 1 & .000 & 1.501 \\
\hline Constant & -.868 & .444 & 3.816 & 1 & .051 & .420 \\
\hline
\end{tabular}

Source: Research data processed by authors with statistical program SPSS

The column B shows the direction of the link between the dependent variable (PSH) and independent variables (SP, VP, VEP). All of them show a positive number and thus a positive connection. Column $\operatorname{Exp}(\mathrm{B})$ shows the intensity of the link between the dependent variable and independent variables.

The coefficients of the variable VP and VEP are statistically significant, for a p-value significance threshold $<0.05$.

There is a direct, positive connection between VP and PSH. Thus, people aged 18-35 are interested in using IoT applications and devices 2.6 times more than people belonging to the age group 36-65 years. As indicated by general studies on the adoption of IoT in Romania (ANCOM, 2019), but also by specific studies on the adoption of smart home solutions (Zanocco et al., 2020), age is a determining factor. Young people with digital skills, a high degree of knowledge and information, being up to date with technological discoveries and progress in this field, choose to use such devices, rather than other age groups, such as the baby boomers generation (born between 1946-1964) and generation $\mathrm{X}$ (born between 1965-1979). The main factor that prevents these categories for using smart home technologies is the concern for personal data protection, a sensitive topic when it comes to new technologies (Jungwoo, Yuri and Daeho, 2018).

There is a direct, positive connection between VEP and PSH. People are more interested in using IoT applications and devices as their revenue grows. Although, in general, people associate IoT with savings and the rational use of electricity, people with lower incomes prefer to save at the expense of joining new technologies, regardless of the benefits they could bring, as other studies indicate (Zanocco et.al, 2020).

In contrast, the coefficient of the variable SP is not statistically significant, because the significance threshold $\mathrm{p}$-value $=0.969$ is very high $(96.9 \%)$, so a very low probability of guaranteeing the significance of the parameter, respectively $3.1 \%$. The explanation lies in the fact that the sample is relatively balanced from this point of view, and the sex of the users does not determine the choice to use smart home devices. As other research in the field shows, there are differences between genders that are not related to the choice of using, but to the reasons for choosing or the criteria applied to choose certain brands or certain functionalities of the devices. For example, research by Jungwoo, Yuri, and Daeho (2018) indicates that males tip the scales in choosing IoT devices based on their usefulness, and females pay more attention to device compatibility.

The model passed the set of diagnostic tests relatively comfortably, as presented in table no. 4. The model is significant, according to the Omnibus test (table no. 4) of the model coefficients. The model also explains between 7.9\% - Cox \& Snell R Square (Cox and Snell, 1989) and 13\% - Nagelkerke R Square (Nagelkerke, 1991) variation in the use of devices and applications that allow remote control and monitoring (table no. 4), 82.2\% of cases being correctly classified. The value of the Hosmer and Lemeshow test (Hosmer and Lemeshow, 2000) supports the model, with a good fit suggested by a value $p>0.05(p=0.26)$. 
Table no. 4. Diagnostic tests of the binary logistic regression model

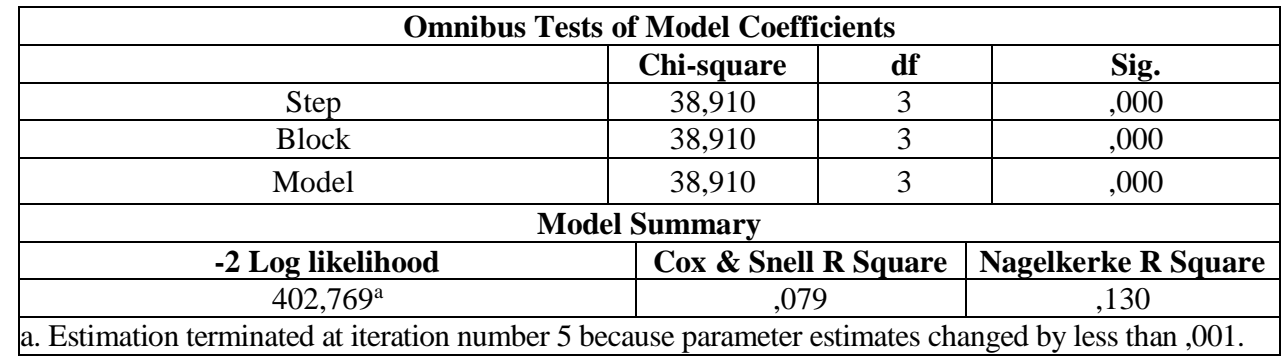

Source: Research data processed by authors with statistical program SPSS

\section{Conclusions}

IoT-based smart home solutions focus on increasing the home comfort, improving the quality of life and enhancing personal experience. In recent years, these solutions have become more popular, more accessible and easier to use through the development of information technology.

As we indicated in the article, issues regarding the architecture of IoT solutions related to the smart home category and those regarding the advantages, benefits, but also challenges and security issues of IoT solutions for smart homes have been frequently addressed in the literature, but issues regarding the degree of understanding the concept and the extent to which these applications are adopted and used have been less approached. Also, the local literature does not deal with issues related to the adoption of these solutions in our country. To cover these gaps identified in the literature, we presented in this article the results of a research that allowed us to discover the level of understanding the IoT concept and the adoption of IoT solutions for smart home by Romanians from different socio-demographic categories.

The key to successfully adopting these technologies is to understand the reasons why people might use them, the features they need, the problems they have identified and the barriers to accepting them, and we have identified all of these in this research.

Although, the Internet of Things is still at the beginning in terms of its applicability in Romania, most of the respondents to our questionnaire (82\% of the 471 respondents) stated they use IoT devices and applications that allow remote control and monitoring. Respondents in our study use such solutions for smart TVs, ventilation and air conditioning systems, access, safety and surveillance systems and heating systems. The main benefits of adopting these solutions have been related to the fact that they save time and energy, make their lives easier and improve the comfort of their homes, and identified problems include technology dependence, high cost of devices, privacy, and information security issues.

Also, we note there are still many obstacles that need to be overcome, and our respondents have also identified problems especially related to the data used throughout the process. At the same time, new technologies and synergies have the potential to address them, such as $5 \mathrm{G}$ technology, which brings the benefit of an increased Internet speed, as well as the use of artificial intelligence (AI), which helps both predictability and making the best decisions.

To identify the relationship between certain determinants (sex, age, income) and the option to use IoT smart home solutions, we used the binary logistic regression model, showing that 
people in the age group 18-35 are more interested in using IoT applications and devices, compared to people belonging to age group 36-65 years. They are also more interested in using IoT applications and devices as their revenues grow; that is naturally, given that most Romanians cannot afford these IoT solutions.

Taking into account the data was obtained by using a web-based survey among the personal contacts of authors and the main limitation of our research is the non-representativeness of the sample, we consider that future research developed among large survey sample could provide a better understanding of the IoT users' attitude and perception.

Also, in future analyzes, the binary logistic regression model could include as dependent variables the environment (urban or rural) in which the house is located, the number of family members living in it and their level of education, as well as the average monthly income of the household, not only those of the respondents. We specify that we did not include in this model the area (rural or urban) within the house is located, most of the respondents $(89.5 \%)$ residing in urban areas. We also did not include the level of education, given that most respondents have undergraduate and postgraduate studies. Other research (van der Zeeuw, van Deursen and Jansen, 2020) shows that the level of education does not influence the attitude towards the use of smart devices for housing, but rather the degree of adaptation and operational skills of the individual has an impact on perceiving IoT technology. For people with advanced operating skills, using IoT devices is perceived as a hobby. They explore all the features offered by IoT and create their ecosystems in their own homes by combining several smart devices. On the other hand, in the case of people with not very developed operating skills, the use of IoT smart home solutions is limited to basic functions. The latter choose to purchase IoT technologies under the influence of external factors, such as recommendations from friends or family, and need help with installation and programming.

Given that our research was initiated at the beginning of the coronavirus pandemic, we did not know the consequences at that time and did not take this into account. Future research should take into account the fact that, against the background of long quarantine periods, people began to discover the new lifestyle, based on working from home, online school and a longer time spent at home, and this lifestyle can have the effect of changing perception regarding the acquisition and adoption of smart technologies in homes.

\section{References}

ANCOM, 2019. Strategia 5G pentru România. [pdf] Available at: <https://www.ancom.ro/ uploads/articles/Strategia\%205G_rev\%2010_06_2019\%20-\%20final\%20no\%20track.pdf> [Accessed 7 December 2020].

Anstee, D., 2019. Rise of the Internet of Things (IoT). [online] TechRadar. Available at: <https://www.techradar.com/news/rise-of-the-internet-of-things-iot> [Accessed 20 November 2020].

Ashton, K., 2009. That "Internet of Things" Thing. RFID Journal, 22(7), pp.97-114.

Atzori, L., Iera, A. and Morabito, G., 2010. The Internet of Things: A Survey. Computer Networks, 54(15), pp.2787-2805.

Ben-Daya, M., Hassini, E. and Bahroun, Z., 2017. Internet of Things and Supply Chain Management: A Literature Review. International Journal of Production Research, 57(3), pp.1-24. https://doi.org/10.1080/00207543.2017.1402140. 
Bing, X., 2014. Key IoT Technology and Application Research. Applied Mechanics and Materials, 543, pp.3411-3414.

Chen, Y.-Q., Zhou, B., Zhang, M. and Chen, C.-M., 2020. Using IoT Technology for Computer-Integrated Manufacturing Systems in the Semiconductor Industry. Applied Soft Computing Journal, 89(C), 106065. https://doi.org/10.1016/j.asoc.2020.106065.

Columbus, L., 2018. 10 Charts that will Challenge your Perspective of IoT's Growth. [online] Forbes. Available at: <https://www.forbes.com/sites/louiscolumbus/ 2018/06/ 06/10-charts-that-will-challenge-your-perspective-of-iots-growth/?sh=7abe785e3ecc> [Accessed 20 November 2020].

Cox, D.R. and Snell, E.J. 1989. Analysis of Binary Data. 2nd ed. London: Chapman and Hall/CRC.

Das, S., Lee, S.-H., Kumar, P., Kim, K.-H., Lee, S.S. and Bhattacharya, S.S., 2019. Solid Waste Management: Scope and the Challenge of Sustainability. Journal of Cleaner Production, 228, pp.658-678. https://doi.org/10.1016/j.jclepro.2019.04.323.

Dhana Shree, K., Janani, B., Reenadevi, R. and Rajesh, R., 2019. Garbage Monitoring System Using Smart Bins. International Journal of Scientific and Technology Research, 11(8), pp.1921-1925.

Dian, F.J., Vahidnia, R. and Rahmati, A., 2020. Wearables and the Internet of Things (IoT), Applications, Opportunities, and Challenges: A Survey. IEEE Access, 8, pp.6920069211. https://doi.org/10.1109/ACCESS.2020.2986329.

Elkhodr, M., Shahrestani, S. and Cheung, H., 2013. The Internet of Things: Vision \& Challenges. In: IEEE 2013 Tencon - Spring Conference Proceedings. Sydney, Australia, 17-19 April 2013. New Jersey: IEEE. pp.218-222.

Fortune Business Insights, 2020. Smart Home Market Size, Share \& Industry Analysis, By Product and Regional Forecast, 2019-2026. [online] Fortune Business Insights. Available at: <https://www.fortunebusinessinsights.com/enquiry/request-samplepdf/smart-home-market-101900> [Accessed 20 November 2020].

Gao, L. and Bai, X., 2014. A Unified Perspective on the Factors Influencing Consumer Acceptance of Internet of Things Technology. Asia Pacific Journal of Marketing and Logistics, 26(2), pp.211-231. https://doi.org/10.1108/APJML-06-2013-0061.

Gigli, M. and Koo, S., 2011. Internet of Things: Services and Applications Categorization. Advances in Internet of Things, 1(2), pp.27-31. https://doi.org/10.4236/ait.2011.12004.

Gubbi, J., Buyya, R., Marusic, S. and Palaniswami, M., 2013. Internet of Things (IoT): A Vision, Architectural Elements, and Future Directions. Future Generation Computer Systems, 29(7), pp.1645-1660. http://dx.doi.org/10.1016/j.future.2013.01.010.

Horrigan, B., 1987. The Home of Tomorrow: 1927-45. In: J. Corn, ed. Imagining Tomorrow: History Technology and the American Future. Cambridge: MIT Press. pp.137-163.

Hosmer, D.W. and Lemeshow, S., 2000. Applied Logistic Regression. Hoboken: John Wiley \& Sons, Inc.

Hsu, C.L. and Lin, J.C.C, 2016. An Empirical Examination of Consumer Adoption of Internet of Things Services: Network Externalities and Concern for Information Privacy Perspectives. Computers in Human Behavior, 62, pp.516-527. http://doi.org/10.1016/ j.chb.2016.04.023. 
Ibarra-Esquer, J.E., González-Navarro, F.F., Flores-Rios, B.L., Burtseva, L. and AstorgaVargas, M.A., 2017. Tracking the Evolution of the Internet of Things Concept Across Different Application Domains. Sensors, 17(6), 1379. https://doi:10.3390/s17061379.

INS, 2020. Câștigul salarial mediu lunar. [online] Institutul Național de Statistică. Available at: <https://insse.ro/cms/ro/tags/comunicat-castig-salarial?page $=1>$ [Accessed 28 December 2020].

Janik, A., Ryszko, A. and Szafraniec, M., 2020. Scientific Landscape of Smart and Sustainable Cities Literature: a Bibliometric Analysis. Sustainability 12(3), 779. http://doi.org/10.3390/su12030779.

Johannesen, N.J., Kolhe, M. and Goodwin, M., 2019. Relative Evaluation of Regression Tools for Urban Area Electrical Energy Demand Forecasting. Journal of Cleaner Production, 218, pp.555-564. https://doi.org/10.1016/j.jclepro.2019.01.108.

Jungwoo, S., Yuri, P. and Daeho, L., 2018. Who Will be Smart Home Users? An Analysis of Adoption and Diffusion of Smart Homes. Technological Forecasting \& Social Change,134(C), pp.246-253. http://doi: 10.1016/j.techfore.2018.06.029.

Le, Q., Nguyen, H. and Barnett, T., 2012. Smart Homes for Older People: Positive Aging in a Digital World. Future Internet, 4(4), pp.607-617. https://doi.org/10.3390/fi4020607.

Lee, E.J. and Park, S.J., 2020. A Framework of Smart-Home Service for Elderly's Biophilic Experience. Sustainability, 12, 8572. https://doi:10.3390/su12208572.

Lee, I. and Lee, K., 2015. The Internet of Things (IoT): Applications, Investments, and Challenges for Enterprises. Business Horizons, 58(4), pp.431-440. https://doi.org/ 10.1016/j.bushor.2015.03.008.

Li, Y., Gao, M., Yang, L., Zhang, C., Zhang, B. and Zhao, X., 2020. Design of and Research on Industrial Measuring Devices Based on Internet of Things Technology. Ad Hoc Network, 102, 102072. https://doi.org/10.1016/j.adhoc.2020.102072.

Lia, M., Gub, W., Chen, W., Hed, Y., Wud, Y. and Zhange, Y., 2018. Smart Home: Architecture, Technologies and Systems. Procedia Computer Science, 131, pp.393-340.

Lynn, T., Endo, P.T., Ribeiro, A.M.N.C., Barbosa, G.B.N. and Rosati, P., 2020. The Internet of Things: Definitions, Key Concepts, and Reference Architectures. In: T. Lynn, J. Mooney, B. Lee and P. Endo, (eds). The Cloud-to-Thing Continuum. Palgrave Studies in Digital Business \& Enabling Technologies. Cham: Palgrave Macmillan. pp.1-22.

Madakam, S., Ramaswamy, R. and Tripathi, S., 2015. Internet of Things (IoT): A Literature Review. Journal of Computer and Communications, 3(5), pp.164-173. https://10.4236/jcc.2015.35021.

Mordor Intelligence, 2020a. Consumer IoT Market - Growth, Trends, and Forecasts (20202025). [online] Mordor Intelligence. Available at: <https://www.mordorintelligence. com/industry-reports/consumer-iot-market> [Accessed 20 November 2020].

Mordor Intelligence, 2020b. Smart Homes Market - Growth, Trends, and Forecast (20202025). [online] Mordor Intelligence. Available at: <https://www.mordorintelligence. com/industry-reports/global-smart-homes-market-industry?gclid=CIjd6MXjyd YCFYYDKgod4ZQFaw> [Accessed 20 November 2020].

Muthu, B.A., Sivaparthipan, C.B., Manogaran, G., Sundarasekar, R., Kadry, S., Shanthini, A. and Dasel, A., 2020. IoT Based Wearable Sensor for Diseases Prediction and Symptom Analysis in Healthcare Sector. Peer Peer Netw, 13(1), pp.1-12. 
Nagelkerke, N.J.D., 1991. A Note on a General Definition of the Coefcient of Determination. Biometrika, 78(3), pp.691-692.

Nivetha, R., Preethi, S., Priyadharshini, P., Shunmugapriya, B., Paramasivan, B. and Naskath, J., 2020. Smart Health Monitoring System Using IoT for Assisted Living of Senior and Challenged People. International Journal of Scientific and Technology Research, 9(2), pp.4285-4288.

Nižetić, S., Šolić, P., López-de-Ipiña González-de-Artaza, D. and Patrono, L., 2019. Internet of Things (IoT): Opportunities, Issues and Challenges towards a Smart and Sustainable Future. Journal of Cleaner Production, 274, 122877. https://10.1016/j.jclepro.2020.122877.

Onete, C.B., Pleşea, D.A., Albăstroiu, I., 2017. Opportunities and Challenges of the Internet of Things Related to Consumer. In: R. Pamfilie, V. Dinu, L. Tăchiciu, D. Pleșea and C. Vasiliu, eds. $3^{\text {rd }}$ BASIQ International Conference on New Trends in Sustainable Business and Consumption. Graz, Austria, 31 May - 3 June 2017. Bucharest: ASE. pp.478-486.

Osterrieder, P., Budde, L. and Friedli, T., 2020. The Smart Factory as a Key Construct of Industry 4.0: a Systematic Literature Review. International Journal of Production Economics, 221(C), 107476. https://doi.org/10.1016/j.ijpe.2019.08.011.

Ostrom, A.L., Parasuraman, A., Bowen, D.E., Patricio, L., Voss, C.A. and Lemon, K., 2015. Service Research Priorities in a Rapidly Changing Context. Journal of Service Research, 18(2), pp.127-159. https://doi.org/10.1177/1094670515576315.

Peng, C.-Y.J., Lee, K.L. and Ingersoll, G.M., 2002. An Introduction to Logistic Regression Analysis and Reporting. The Journal of Educational Research,96(1), pp.3-14. https://doi.org/10.1080/00220670209598786.

Perera, C., Qin, Y., Estrella, C.J., Reiff-Marganiec, S. and Vasilakos, A.V., 2017. Fog Computing for Sustainable Smart Cities: A Survey. ACM Computing Surveys, 50(3), pp.1-43.

Porru, S., Misso, F.E., Pani, F.E. and Repetto, C., 2020. Smart Mobility and Public Transport: Opportunities and Challenges in Rural and Urban Areas. Journal of Traffic and Transportation Engineering, 7(1), pp.88-97. https://doi.org/10.1016/ j.jtte.2019.10.002.

Porter, M.E. and Heppelmann, J.E., 2014. How Smart, Connected Products are Transforming Competition. Harvard Business Review, 92(11), pp.64-88.

Research Reports World, 2020. 2020-2025 Global Smart Home IoT Market Report Production and Consumption Professional Analysis (Impact of COVID-19). [online] Research Reports World. Available at: <https://www.researchreportsworld.com/20202025-global-smart-home-iot-market-16933840 > [Accessed 20 November 2020].

Ricquebourg, V., Menga, D., Durand, D., Marhic, B., Delahoche, L. and Loge, C., 2006. The Smart Home Concept: Our Immediate Future. In: Proceedings of the 2006 1st IEEE International Conference on E-Learning in Industrial Electronics. Hammamet, Tunisia, 18-20 December 2006. New Jersey: IEEE. pp.23-28.

Rishav, M., Maity, R., Ghosh, D., Ganesh, V.N. and Sivakumar, D., 2019. Internet of Thing based Smart Power Grid for Smart City. International Journal of Recent Technology and Engineering, 8(1), pp.450-453. 
Risteska Stojkoska, L.B. and Trivodaliev, V.K., 2017. A Review of Internet of Things for Smart Home: Challenges and Solutions. Journal of Cleaner Production, 140(3), pp.1454-1464. https://doi.org/10.1016/j.jclepro.2016.10.006.

Saki, M., Abolhasan, M. and Lipman, J.E., 2020. A Novel Approach for Big Data Classification and Transportation in Rail Networks. IEEE Transactions on Intelligent Transportation Systems, 21(3), pp.1239-1249.

Schlick, J., Ferber, S. and Hupp, J., 2013. IoT Applications - Value Creation for Industry. Aalborg: River Publisher.

Shen, X., Fantacci, R. and Chen, S., 2020. Internet of Vehicles. IEEE, 108(2), pp.242-245.

Shin, D., 2014. A Socio-technical Framework for Internet-of-Things Design: A HumanCentered Design for the Internet of Things. Telematics and Informatics, 31(4), pp.519-531.

Shin, D.-H. and Park, Y.J., 2017. Understanding the Internet of Things Ecosystem: MultiLevel Analysis of Users, Society and Ecology. Digital Policy, Regulation and Governance, 19(1), pp.77-100. https://doi.org/10.1108/DPRG-07-2016-0035.

Sicari, S., Rizzardi, A., Grieco, L.A. and Coen-Porisini, A., 2015. Security, Privacy and Trust in Internet of Things: The Road Ahead. Computer Networks, 76, pp.146-164. https://doi.org/10.1016/j.comnet.2014.11.008.

Sowah, A.R., Boahene, E.D., Owoh, C.D., Addo, R., Mills, A.G., Owusu-Banahene, W., Buah, G. and Sarkodie-Mensah, B., 2020. Design of a Secure Wireless Home Automation System with an Open Home Automation Bus (OpenHAB 2) Framework. Journal of Sensors, 8868602. https://doi.org/10.1155/2020/8868602.

Strengers, Y., 2013. Smart energy technologies in everyday life: Smart Utopia? Basingstoke: Palgrave Macmillan.

van der Zeeuw, A., van Deursen, A.J.A.M. and Jansen, G., 2020. How to Apply IoT Skills at Home: Inequalities in Cultural Repertories and its Interdependency Chains. Poetics, 83, 101486. https://doi.org/10.1016/j.poetic.2020.101486.

Weyrich, M. and Ebert, C., 2016. Reference Architectures for the Internet of Things. IEEE Software 33(1), pp.112-116. https://doi.org/10.1109/MS.2016.20.

Whitmore, A., Agarwal, A. and Li, D.X., 2015. The Internet of Things - A Survey of Topics and Trends. Information Systems Frontiers, 17(2), pp.261-274. https://doi.org/10.1007/s10796-014-9489-2.

Wirtz, W.B., Weyerer, C.J. and Schichtel, T.F., 2019. An Integrative Public IoT Framework for Smart Government. Government Information Quarterly, 36(2), pp.333-345. https://doi.org/10.1016/j.giq.2018.07.001.

Yang, H., Lee, W. and Lee, H, 2018. IoT Smart Home Adoption: The Importance of Proper Level Automation. Journal of Sensors, 6464036, pp.1-11. https://doi.org/10.1155/ 2018/6464036.

Zanocco, C., Flora, F., Rajagopal, R. and Boudet, H., 2020. Exploring the Effects of California's COVID-19 Shelter-In-Place Order an Household Energy Practice and Intention to Adopt Smart Home Technologies. Renewable and Sustainable Energy Reviews, 139. https://doi.org/10.1016/j.rser.2020.110578.

Zhang, L, Yang, L., Wang, Z. and Yan, D., 2020. Sports Wearable Device Design and Health Data Monitoring based on Wireless Internet of Things. Microprocessors and Microsystems, 103423 (in press). https://doi.org/10.1016/j.micpro.2020.103423. 